\title{
Primary resistance to first-generation EGFR- TKls induced by MDM2 amplification in NSCLC
}

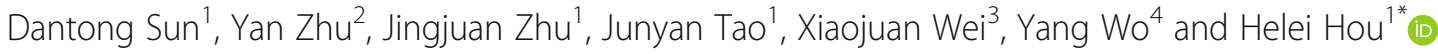

\begin{abstract}
Introduction: Targeted therapy for NSCLC is rapidly evolving. EGFR-TKIs benefit NSCLC patients with sensitive EGFR mutations and significantly prolong survival. However, $20-30 \%$ of patients demonstrate primary resistance to EGFRTKIs, which leads to the failure of EGFR-TKI treatment. The mechanisms of primary resistance to EGFR-TKIs require further study.

Methods: Targeted sequencing was used for the detection of genomic alterations among patients in our center. Regular cell culture and transfection with plasmids were used to establish NSCLC cell lines over-expressing MDM2 and vector control. We used the MTT assays to calculate the inhibition rate after exposure to erlotinib. Available datasets were used to determine the role of MDM2 in the prognosis of NSCLC.

Results: Four patients harboring concurrent sensitive EGFR mutations and MDM2 amplifications demonstrated insensitivity to EGFR-TKIs in our center. In vitro experiments suggested that MDM2 amplification induces primary resistance to erlotinib. Over-expressed MDM2 elevated the IC50 value of erlotinib in HCC2279 line and reduced the inhibition rate. In addition, MDM2 amplification predicted a poor prognosis in NSCLC patients and was associated with a short PFS in those treated with EGFR-TKIs. The ERBB2 pathway was identified as a potential pathway activated by MDM2 amplification could be the focus of further research.

Conclusion: MDM2 amplification induces the primary resistance to EGFR-TKIs and predicts poor prognosis in NSCLC patients. MDM2 may serve as a novel biomarker and treatment target for NSCLC. Further studies are needed to confirm the mechanism by which amplified MDM2 leads to primary resistance to EGFR-TKIs.
\end{abstract}

Keywords: MDM2 amplification, Primary resistance, EGFR-TKIs, NSCLC, Prognosis

\section{Introduction}

Lung cancer ranks first among all malignancies in cancer-related mortality, and the 5-year overall survival (OS) is lower than $20 \%$ in China (Allemani et al. 2018). Non-small-cell lung cancer (NSCLC) consists of nearly 85\% of lung cancer cases (Hou et al. 2019a) and targeted therapeutics based on driver mutations of NSCLC, such as mutations of epidermal growth factor receptor (EGFR) (Santoni-Rugiu et al. 2019) and anaplastic

\footnotetext{
* Correspondence: houhelei@qdu.edu.cn

${ }^{1}$ Precision Medicine Center of Oncology, The Affiliated Hospital of Qingdao University, 16 Jiangsu Road, Qingdao 266000, Shandong, China

Full list of author information is available at the end of the article
}

lymphoma kinase (ALK) (Golding et al. 2018), have significantly prolonged the survival of patients. Approximately $50 \%$ of Asian NSCLC patients harbor EGFR mutations, while $11-16 \%$ of patients in Western countries (Recondo et al. 2018) benefit from treatment with first-generation EGFR-TKIs. Mutations were detected in exons 18 to 21 of EGFR, while the majority of EGFR mutations are exon 19 deletions and exon 21 substitutions of leucine for arginine (L858R) (Recondo et al. 2018; Castellanos et al. 2017). First-generation EGFRTKIs, including gefitinib and erlotinib, have benefited NSCLC patients, especially Asian patients. According to the IRESSA Pan-Asia Study, patients treated with

(c) The Author(s). 2020 Open Access This article is licensed under a Creative Commons Attribution 4.0 International License, which permits use, sharing, adaptation, distribution and reproduction in any medium or format, as long as you give appropriate credit to the original author(s) and the source, provide a link to the Creative Commons licence, and indicate if changes were made. The images or other third party material in this article are included in the article's Creative Commons licence, unless indicated otherwise in a credit line to the material. If material is not included in the article's Creative Commons licence and your intended use is not permitted by statutory regulation or exceeds the permitted use, you will need to obtain permission directly from the copyright holder. To view a copy of this licence, visit http://creativecommons.org/licenses/by/4.0/. 
gefitinib demonstrated longer progression-free survival (PFS) than those treated with standard chemotherapy regimens, including carboplatin and paclitaxel $(9.5$ months versus 6.3 months) (Mok et al. 2009).

Unfortunately, patients may develop resistance to first generation EGFR-TKIs, which leads to treatment failure. In addition to acquired resistance, multiple genomic alterations have been proven to be associated with primary resistance to EGFR-TKIs, such as the pre-existing T790M mutation (Inukai et al. 2006; Lee et al. 2014), insulin-like growth factor 1 receptor (IGF1R) mutation (Sharma et al. 2010), MET amplification (Turke et al. 2010), hepatocyte growth factor (HGF) mutation (Yano et al. 2008) and mutations leading to sustained activated signaling in other pathways, including the PI3K/AKT pathway (Tan et al. 2015). In our previous review, we identified the potential relationship between murine double minute 2 (MDM2) amplification and primary resistance to EGFR-TKIs. MDM2 amplification may activate the bypass signaling pathways, inhibit tumor cell apoptosis, promote the epithelial to mesenchymal transition (EMT) process and tumor angiogenesis and contribute to primary resistance to EGFR-TKIs (Hou et al. 2019b). Therefore, we performed this study to confirm our hypothesis that $M D M 2$ amplification contributes to the primary resistance to first-generation EGFR-TKIs in NSCLC.

\section{Methods}

\section{Clinical cases and targeted sequencing}

Patients with advanced NSCLC (stage IIIB to IV) seen at our center from July 2015 to March 2018 were selected for targeted sequencing with the patients' consent $(n=$ 141). The detailed sequencing procedure has been described in our previous study (Hou et al. 2018a). Patients harboring concurrent EGFR sensitive mutations and MDM2 amplification were included in this study. All patients were treated with first-generation EGFR-TKIs selected by the patient. The disease evaluation followed Response Evaluation Criteria in Solid Tumors 1.1 (RECIST 1.1). The research was admitted by the Ethics Committee of the Affiliated Hospital of Qingdao University, and the investigations all followed the rules of the Declaration of Helsinki. Written informed consent was signed by all patients when the research began, and all experiments were carried out following the guidelines of the National Health and Family Planning Commission of the PRC.

\section{Cell lines and cell culture}

NSCLC (adenocarcinoma) cell lines were purchased from the cell bank from the Chinese Academy of Sciences (Shanghai, China). EGFR mutations were verified in these cell lines (Gandhi et al. 2009; Li et al. 2007).
The cell lines were cultured in Roswell Park Memorial Institute (RPMI)-1640 medium with 20\% fetal bovine serum (FBS) as well as $1 \% \mathrm{P} / \mathrm{S}(100 \mathrm{IU} / \mathrm{ml}$ penicillin and $100 \mathrm{IU} / \mathrm{ml}$ streptomycin) in a $37^{\circ} \mathrm{C}$ humidified atmosphere with 5\% CO2. All cell lines were tested for mycoplasma and chlamydia, and all subsequent experiments were used the selected cell lines within six generations.

\section{Transfection}

The cell line was divided into two groups and transfected with plasmids expressing MDM2 (LVRU6GPMDM2, Fulengene, Guangzhou, China) or empty vector (LVRU6GP-Vector, Fulengene, Guangzhou, China) using Lipofectamine 2000 (Invitrogen, Carlsbad, CA). The transfection process lasted for $48 \mathrm{~h}$, and then the cells were harvested for subsequent experiments.

\section{RNA extraction and quantitative real-time PCR (qPCR)}

TRIzol (Invitrogen, Carlsbad, CA) was used to extract the total RNA from the cultured cells. PrimeScript ${ }^{\mathrm{Tm}} \mathrm{RT}$ Kit (TaKaRa, Otsu, Japan) was used to perform the cDNA synthesis. The qPCR was performed by an FTC3000p Realtime PCR system (Funglyn Biotech, Shanghai, China) using SYBR Premix EX Taq ${ }^{\mathrm{Tm}}$ (TaKaRa, Otsu, Japan). The expression levels of RNA were determined by the comparative $2^{-\Delta \Delta C T}$ method as described in the previous work of our lab (Wang et al. 2015). The PCR primers used in this study are listed in Table S1.

\section{Western blotting}

Cell lysates were centrifuged at $12,000 \mathrm{~g}$ for $20 \mathrm{~min}$ at $4{ }^{\circ} \mathrm{C}$, and the BCA protein assay reagent kit (Beyotime, Shanghai, China) was used to determine the protein concentrations of the supernatants. The supernatants were mixed with $5 \times$ SDS loading buffer and heated at $95^{\circ} \mathrm{C}$ for $5 \mathrm{~min}$. Twenty milligrams of total protein from each sample was separated by SDS-PAGE and transferred to $0.22-\mu \mathrm{m}$ nitrocellulose (NC) membranes. The membranes were blocked with $5 \%$ nonfat dry milk in TBST for $2 \mathrm{~h}$ and incubated overnight with the primary antibody. After being washed three times for $30 \mathrm{~min}$ with TBST, the membrane was incubated with HRP conjugated secondary antibodies for $2 \mathrm{~h}$ at room temperature. We used the ECL reagent (Pierce, Rockford, IL, USA) to visualize the immunoreactive blots. The information of antibody information was concluded in Table S1.

\section{MTT assay}

Transfected cells were seeded (5000 cells/well) in 96well plates overnight and exposed to proportionally diluted erlotinib $\mathrm{HCl}$ (OSI-744) purchased from Selleck ranging from $1 \mu \mathrm{M}$ to $128 \mu \mathrm{M}$. After $24 \mathrm{~h}$ incubation, 20 $\mathrm{ml}$ of MTT solution $(5 \mathrm{mg} / \mathrm{ml})$ was added to the 
medium, and the cells were incubated at $37^{\circ} \mathrm{C}$ for another $4 \mathrm{~h}$. Then we discarded the culture medium and added $150 \mathrm{ml}$ of DMSO to each well. Absorbance (A) was measured at $570 \mathrm{~nm}$ using an ELISA plate reader, with background subtraction measurements done at $630 \mathrm{~nm}$. The inhibition rate was calculated as described in our previous study (Hou et al. 2018b): Inhibition rate $=1-[(\mathrm{A} 570-\mathrm{A} 630)$ of treated cells/(A570A630) of control cells].

\section{Bioinformatic analyses}

Survival analyses were performed online with cBioportal for Cancer Genomics and GEPIA (Tang et al. 2017). In addition, we divided lung adenocarcinoma (LUAD) patients from The Cancer Genome Atlas (TCGA) into two groups, MDM2-high (MDM2-H) and MDM2-low (MDM2-L), and performed Gene Set Enrichment Analysis (GSEA) to acquire the altered signaling pathways between the two groups of patients. (Patients information available at: http://xena.ucsc.edu).

\section{Statistical analyses}

All figures and statistical results in our study were generated by GraphPad Prisma 8.0 software and CorelDRAW 2019. Survival curves were plotted using the Kaplan-Meier method and compared using the log-rank test. $P$ values were two-tailed examined for all tests, and $P<0.05$ was used to define statistical significance.

\section{Results}

\section{Case reports}

In total, 4 patients with stage IIIB to IV NSCLC were reported in this study. Targeted sequencing for these patients revealed that all 4 patients harbored concurrent $M D M 2$ amplification and sensitive EGFR mutations, either deletions of exon 19 or the L858R mutation of exon 21. Patients all selected gefitinib $(250 \mathrm{mg}$, qd) as their first-line treatment given the genomic alterations of EGFR. However, all patients did not reach the promised PFS values in clinical trials including Asian patients, the mean PFS (mPFS) was 6.25 months, ranging from 5.1 months to 8.1 months, and progressive disease was detected in all patients through CT or MRI scans. Patient 1 was a 62-year-old man diagnosed with stage IV LUAD on May 16, 2016, whose disease progressed after 5.2 months of gefitinib treatment. Multiple brain metastases were found by MRI scan, as shown in Fig. 1a. Patient 2, patient 3 and patient 4 had PFS values of 6.9 months, 8.1 months and 5.1 months, respectively. The maximum diameter of the tumor increased by $20 \%$ over the baseline level, and tumor markers were elevated. The change in carcinoembryonic antigen (CEA) level over time in patient 3 is shown in Fig. 1b, and CT scans for patient 2 are shown in Fig. 1a as well. Initial targeted sequencing of the four patients revealed that all patients harbored $M D M 2$ amplification, therefore, we hypothesized that $M D M 2$ amplification may induce primary resistance to EGFR-TKIs and result in a poor prognosis of NSCLC patients harboring sensitive EGFR mutations. The results of targeted sequencing and detailed information of the four patients are listed in Table 1.

\section{MDM2 amplification induces primary resistance to EGFR- TKIs}

We estimated the expression of MDM2 in three NSCLC cell lines harboring EGFR sensitive mutations, including HCC2279, NCI-H3255 and HCC4006 cell lines and HCC2279 cell line were eventually selected for subsequent experiments. The western blotting results for the evaluation of MDM2 expression are shown in Fig. 2a. After transfection with plasmids, we harvested the cells and estimated the relative RNA expression levels of MDM2 between the two groups in HCC2279 cell line. Cells transfected with plasmids expressing MDM2 demonstrated higher expression levels than the vector control group, as shown in Fig. 2d.

After exposure to erlotinib, we compared the inhibition rate of the MDM2 group and vector group in the HCC2279 cell line, as shown in Fig. 2e. As shown in Fig. 2e, the MDM2 group demonstrated the ability to induce primary resistance to EGFR-TKIs, represented by significantly low inhibition rates while exposed to different doses of erlotinib $(1 \mu \mathrm{M}, 2 \mu \mathrm{M}, 4 \mu \mathrm{M}, 8 \mu \mathrm{M}, 32 \mu \mathrm{M}, 64 \mu \mathrm{M}$ and $128 \mu \mathrm{M}$ ). According to previous studies (Li et al. 2007; Yoshida et al. 2015), $10 \mu \mathrm{M}$ erlotinib inhibits the Tyr845 (Src-dependent phosphorylation) and Tyr1068 (autophosphorylation) phosphorylation of EGFR. Therefore, the MDM2 group demonstrated significant resistance to erlotinib compared with the vector group in the HCC2279 cell line before and after the inhibition of EGFR phosphorylation by erlotinib. In addition, MDM2 amplification significantly elevated the IC50 values of erlotinib in the HCC2279 cell line from $36.5 \mu \mathrm{M}(43.4 \mu \mathrm{M}-79.6 \mu \mathrm{M})$ to $57.6 \mu \mathrm{M}(24.1 \mu \mathrm{M}-58.7 \mu \mathrm{M})$.

The western blotting results in Fig. $2 \mathrm{~b}$ verified the transfection process and the expression level of target proteins. MDM2 expression was significantly elevated by transfection. In addition, we examined the expression levels of EGFR, ERK1 and ERK2. The expression of EGFR showed no significant change after transfection. However, ERK1 and ERK2 showed a positive correlation with the elevation of MDM2 expression. The quantified results of western blotting are shown in Fig. 2c.

\section{MDM2 amplification predicts a poor prognosis in NSCLC} MDM2 amplification induces resistance to EGFR-TKIs in NSCLC cell lines, and we further researched the relationship between MDM2 amplification and the 

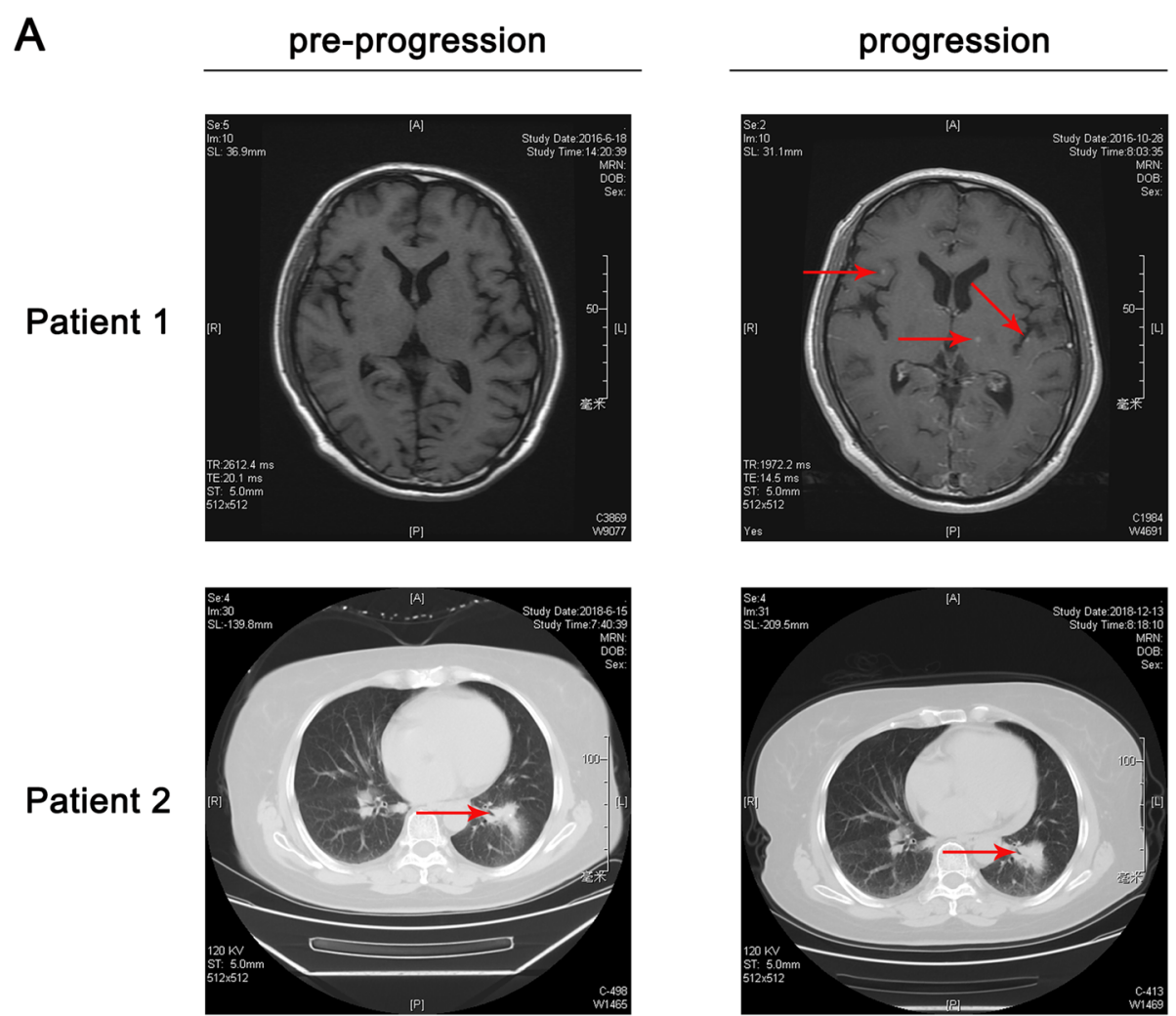

B

Patient 2

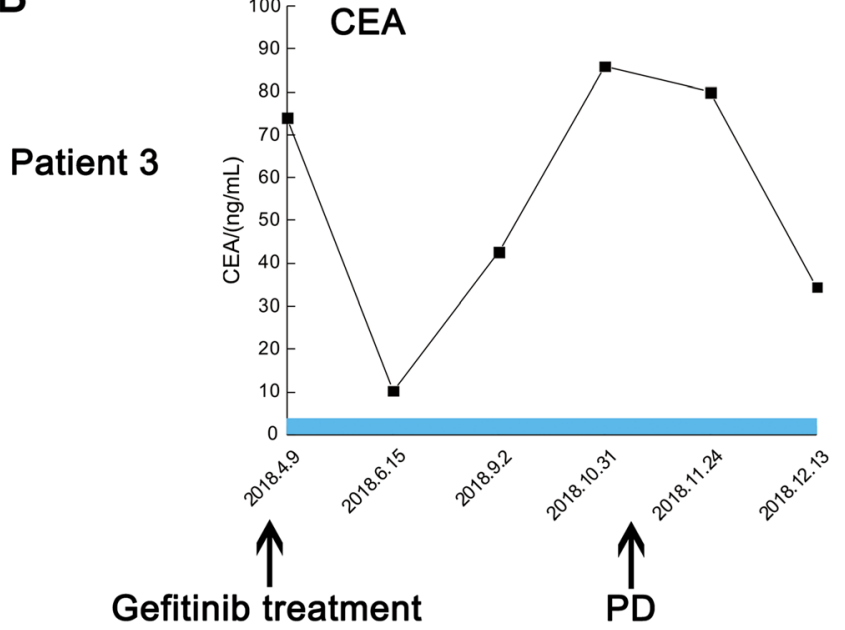

Fig. 1 Basic information for selected patients harboring concurrent alterations of EGFR sensitive mutations and MDM2 amplification. a CT and MRI scans of patients before and after the progression of the disease: new lesions in central nervous system of patient 1 were detected; the primary lesion of patient 2 was evaluated as progressive disease according to RECIST 1.1; $\mathbf{b}$ the carcinoembryonic antigen (CEA) change of patient 3 during the treatment process: CEA of patient 3 elevated drastically after approximately 2 months of gefitinib treatment

prognosis in NSCLC. As shown in Fig. 3a, 20\% of LUAD patients harbored genomic alterations in EGFR, and 6\% of LUAD patients harbored genomic alterations in MDM2. MDM2 amplification is the major alteration and accounts for $85.98 \%$ of all genomic alterations of MDM2. In addition, $1.42 \%$ of LUAD patients harbored concurrent EGFR mutations and MDM2 alterations. As shown in Fig. 3 B1, the concurrent genomic alteration of $E G F R$ and $M D M 2$ demonstrated weak ability in predicting the disease free survival (DFS) of LUAD patients (the survival curve of DFS may discriminate the patients but no statistical significance was found) but patients harboring concurrent genomic alterations of EGFR and $M D M 2$ demonstrated poor OS $(P<0.001)$ according to 
Table 1 Basic characteristics and NGS examination of four patients

\begin{tabular}{|c|c|c|c|c|}
\hline & Patient 1 & Patient 2 & Patient 3 & Patient 4 \\
\hline Age & 62 & 60 & 59 & 67 \\
\hline Gender & male & female & female & male \\
\hline Race & Asian & Asian & Asian & Asian \\
\hline TNM stage & IV & IV & IV & $\| \mathrm{II}$ \\
\hline Pathology & $\begin{array}{l}\text { Moderately differentiated } \\
\text { adenocarcinoma }\end{array}$ & $\begin{array}{l}\text { Invasive } \\
\text { adenocarcinoma }\end{array}$ & $\begin{array}{l}\text { Poorly differentiated } \\
\text { adenocarcinoma }\end{array}$ & $\begin{array}{l}\text { Invasive } \\
\text { adenocarcinoma }\end{array}$ \\
\hline EGFR-TKIs & Gefitinib & Gefitinib & Gefitinib & Gefitinib \\
\hline Regimen & $250 \mathrm{mg}, \mathrm{qd}$ & $250 \mathrm{mg}, \mathrm{qd}$ & $250 \mathrm{mg}, \mathrm{qd}$ & $250 \mathrm{mg}, \mathrm{qd}$ \\
\hline PFS (months) & 5.2 & 6.9 & 8.1 & 5.1 \\
\hline $\begin{array}{l}\text { Genomic } \\
\text { alterations }\end{array}$ & $\begin{array}{l}\text { EGFR Exon } 21 \text { L858R } \\
\text { MDM2 Amplification } \\
\text { TP53 D208G } \\
\text { ERBB4 L770V } \\
\text { BLM D997N }\end{array}$ & $\begin{array}{l}\text { EGFR Exon } 19 \\
\text { Deletion } \\
\text { MDM2 Amplification } \\
\text { CDK4 Amplification } \\
\text { ARID1B Q1312K } \\
\text { NKX2-1 G115S } \\
\text { PTCH1 G1136 } \\
\text { RET R475W }\end{array}$ & $\begin{array}{l}\text { EGFR Exon } 19 \text { Deletion } \\
\text { MDM2 Amplification } \\
\text { EGFR Amplification } \\
\text { CDK4 Amplification } \\
\text { CTIF R77L } \\
\text { APC L1564 }\end{array}$ & $\begin{array}{l}\text { EGFR Exon } 21 \text { L858R } \\
\text { MDM2 Amplification } \\
\text { FLT3 P336T } \\
\text { FYN L411M } \\
\text { FANCL M89| } \\
\text { NCOR1 P347T }\end{array}$ \\
\hline
\end{tabular}

the survival curves shown in Fig. 3 B2. In fact, MDM2 expression itself is a biomarker for predicting the poor DFS $(P=0.007)$ and OS $(P<0.001)$ in NSCLC, as shown in Fig. $3 \mathrm{C} 1$ and $\mathrm{C} 2$. The mean DFS in the MDM2-L group was 38.13 months versus 22 months in the MDM2-H group, and the mean OS was 175 months in the MDM2-L group versus 68.67 months in the MDM2$\mathrm{H}$ group.

MDM2 serves as a potential regulator by affecting EGFRTKI resistance pathways

To determine the potential pathway altered by MDM2 expression and provide more information for further research, we performed GSEA based on data from the TCGA database, as shown in Figure S1A1 to Figure S1A4. These results revealed that MDM2 may activate the ERBB2 pathway and induce primary resistance to EGFR-TKIs via this pathway. In GSEA, the expression of PI3K (nominal $P$ value $=0.018$ ) and SCH1 (nominal $P$ value $=0.034$ ), members of the ERBB2 signaling pathway, was up-regulated, and cell motility regulated by ERBB2 (nominal $P$ value $=0.020$ ) was activated in the MDM2-H group. In addition, the platelet-derived endothelial growth factor (PDGF)-ERK pathway, which also serves as one of the EGFR-TKI resistance pathways, was also activated in the MDM2- $\mathrm{H}$ group (nominal $P$ value = 0.002). MDM2, which is a ubiquitinase of P53, is associated with the ubiquitination of the molecules shown in Fig. S1B through the detection of gene-cloud of biotechnology information (GCBI), including MET and IGF1R, which are tightly associated with the resistance to EGFR-TKIs described above. The protein-protein interaction (PPI) plot is shown in Fig. S1C. We further performed enrichment analysis based on these genes through Metascape (an online tool for enrichment analyses), as shown in Fig. S1D. These genes were closely related to pathways inducing EGFR-TKI resistance, including positive regulation of kinase activity (GO: 0033674) and activation of the EGFR-TKI resistance pathway (hsa01521).

\section{Discussion}

EGFR-TKIs benefit NSCLC patients harboring sensitive EGFR mutations and prolong survival. However, 20-30\% of NSCLC patients harboring sensitive EGFR mutations exhibit primary resistance to EGFR-TKIs (Xu et al. 2016; Zhang et al. 2019). Further research is needed to investigate the mechanisms of primary resistance to EGFRTKIs. As far as we are concerned, our study is the first to confirm the relationship between MDM2 amplification and resistance to first-generation EGFR-TKIs. Four NSCLC patients in our study harboring EGFR sensitive mutations and $M D M 2$ amplification had significantly shortened PFS, which drew our attention towards the initial targeted sequencing done before EGFR-TKI treatment. According to the survival analyses based on data from the TCGA database, MDM2 predicts poor prognosis in NSCLC patients, especially a short OS in patients harboring concurrent EGFR mutations and MDM2 alterations. MDM2, which serves as the biological negative regulator of P53, may be a potential target for further NSCLC treatment.

In vitro data in our study suggested that HCC2279 cells over-expressing MDM2 demonstrated the ability to develop primary resistance to EGFR-TKIs regardless of the EGFR phosphorylation. MDM2 overexpression confers resistance to EGFR-TKIs in NSCLC cell lines, and low expression of MDM2 leads to sensitivity to EGFR- 
A

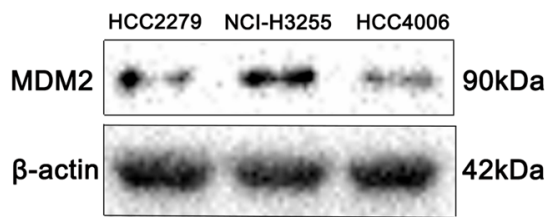

C

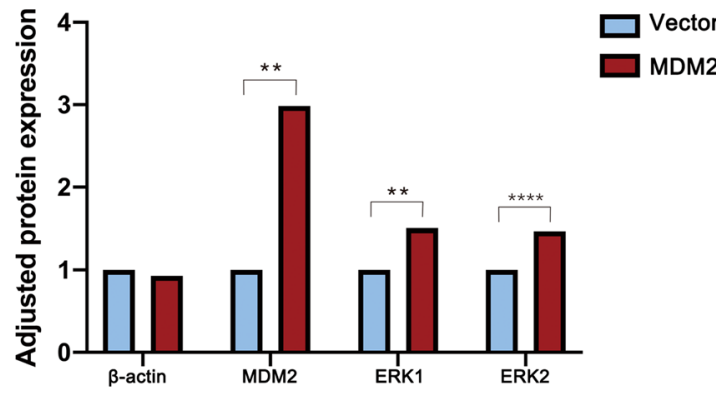

B

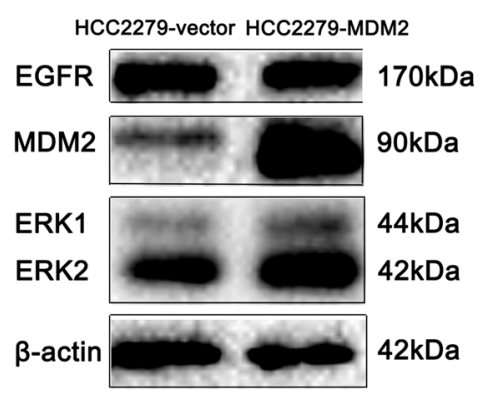

D

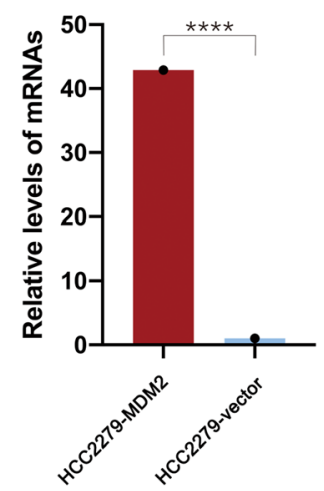

E

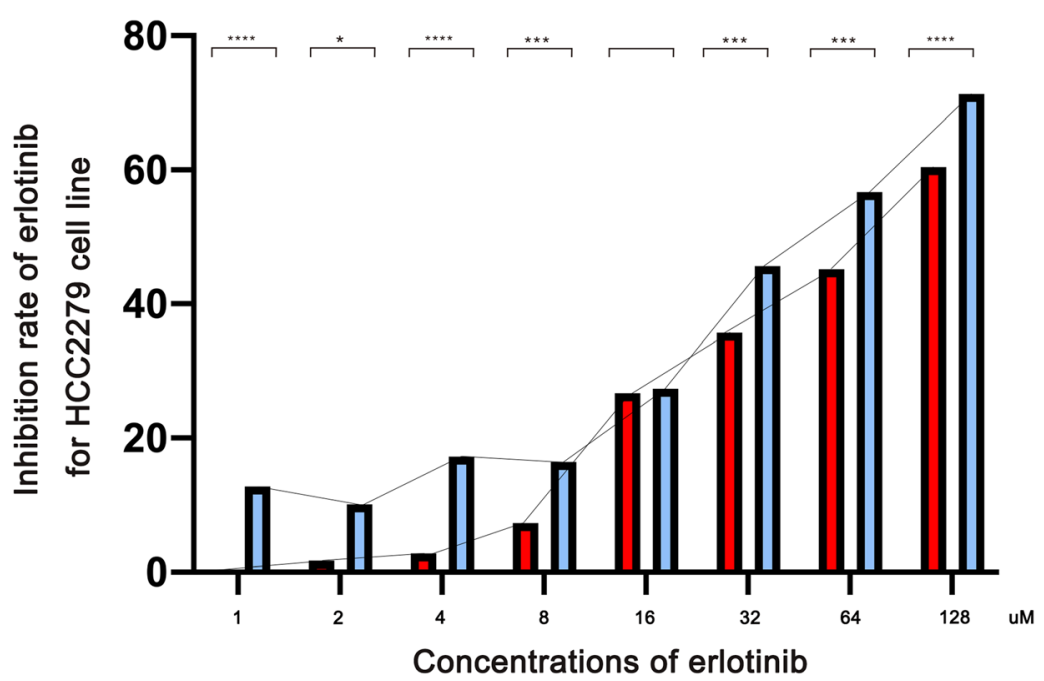

Fig. 2 MDM2 amplification induces the primary resistance to erlotinib. a Western blotting results for the evaluation of MDM2 expression level among NSCLC cell lines: the HCC2279 cell line was selected for the subsequent experiments for the medium expression of MDM2; $\mathbf{b}$ Western blotting results for the target proteins in HCC2279 cell line: $\beta$-actin is the protein encoded by the house-keeping gene and balances the protein concentrations between 2 groups; MDM2 expression was upregulated after the transfection of the plasmids; EGFR expression demonstrates no significant difference between 2 groups; ERK proteins including ERK1 and ERK2 were all upregulated in HCC2279-MDM2 group; c Quantified results for western blotting; d The verification of transfection in HCC2279 cell line: the transcription level of MDM2 gene was highly upregulated in HCC2279-MDM2 group; $\mathbf{e}$ The curve of the inhibition rate after exposure to erlotinib with different concentration through the examination of MTT assays in the MDM2 amplification group and vector control group of HCC2279 cell line: $10 \mathrm{uM}$ erlotinib was set as the medium concentration in this experiment, dramatic resistance to erlotinib could be found in HCC2279-MDM2 group in 1UM, 2uM, 4uM, $8 \mathrm{uM}, 32 \mathrm{uM}, 64 \mathrm{uM}$ and 128uM erlotinib. The inhibition rates were measured via the formula as follow: Inhibition rate = 1-[(A570-A630) of treated cells/(A570A630) of control cells] 


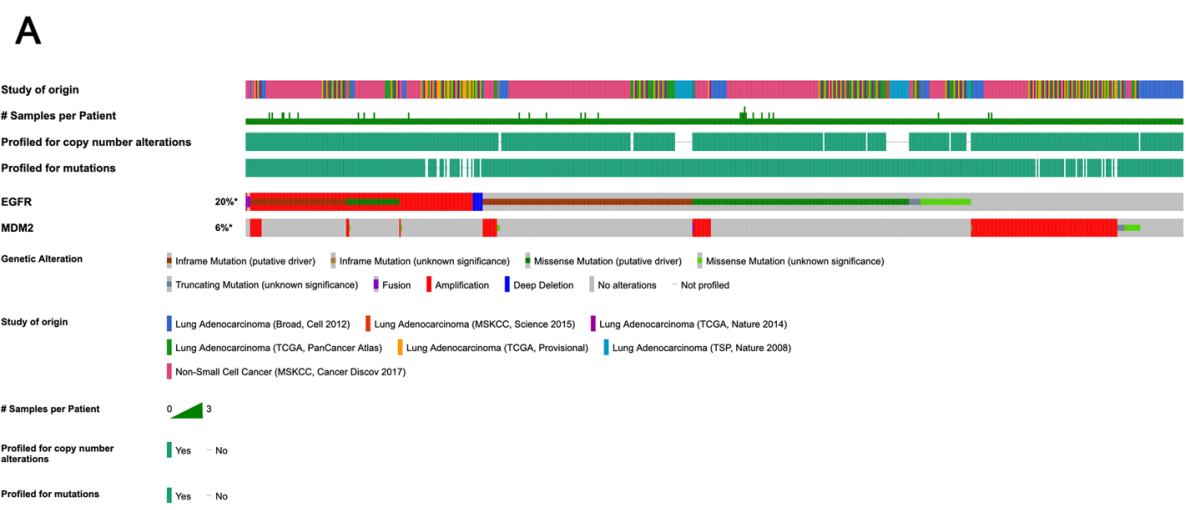

B1

B2
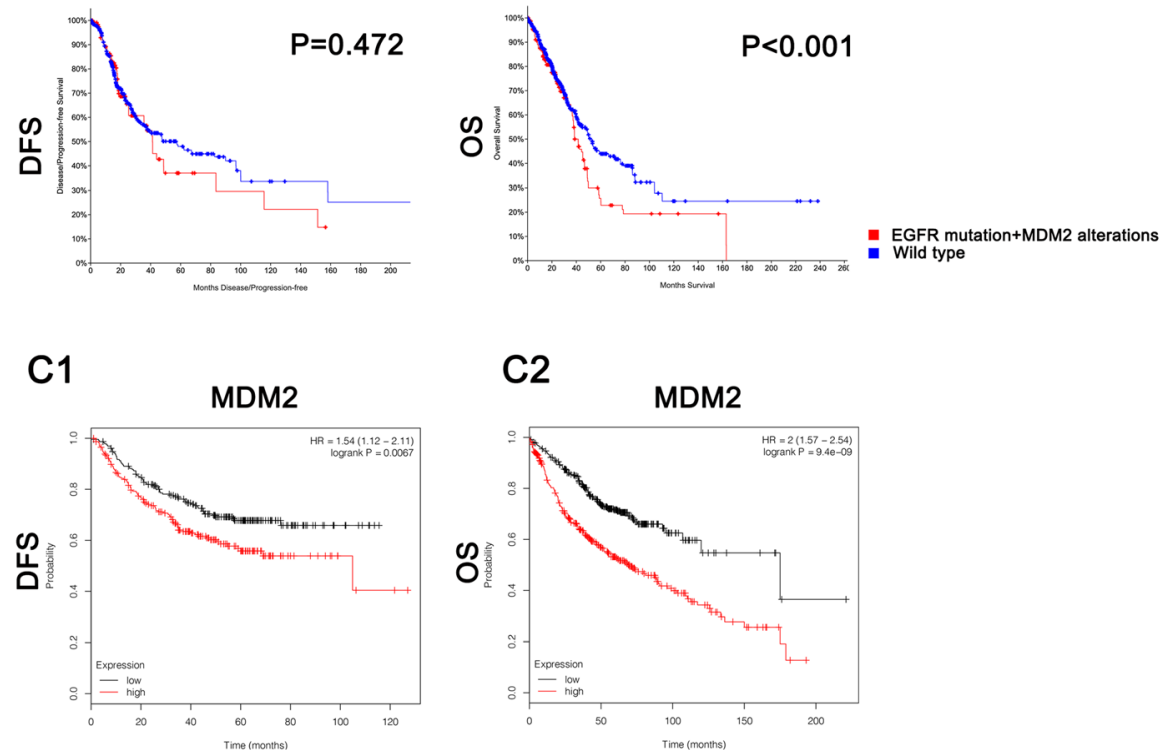

$\mathrm{C} 2$

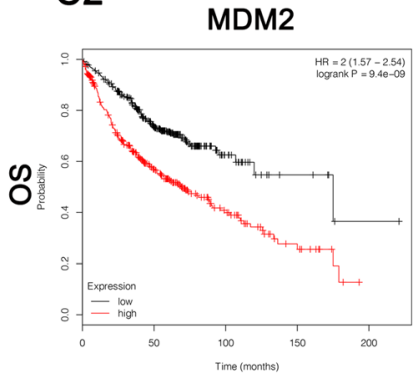

Fig. 3 MDM2 amplification predicts a poor prognosis in NSCLC patients. a The genomic signatures of NSCLC patients derived from cBioportal for Cancer Genomics: 20\% NSCLC patients were detected harboring EGFR alterations and 6\% of them were detected harboring MDM2 alterations; B1B2. The survival analyses of NSCLC patients grouped by genomic signatures of EGFR and MDM2 (DFS: disease free survival; OS: overall survival): NSCLC patients harboring the concurrent alterations of EGFR and MDM2 have a poor OS $(P<0.001)$; $C 1-C 2$. The survival analyses of NSCLC patients grouped by MDM2 expression: NSCLC patients with higher expression of MDM2 demonstrate poor DFS $(P=0.0067)$ and OS $(P<0.0001)$

TKIs. In this study, the MDM2-overexpressing cell line elevated the IC50 value of EGFR-TKIs and significantly reduced the inhibition rate. This phenomenon led us to investigate the potential pathways altered by MDM2 expression that may be associated with primary resistance to EGFR-TKIs. ERBB2 amplification was proven to be closely associated with resistance to EGFR-TKIs (Takezawa et al. 2012; Kim et al. 2019). In vitro experiments revealed that ERBB2-overexpressing cell lines were resistant to erlotinib. In addition, ERBB2 amplification was detected in human samples that demonstrated resistance to EGFR-TKIs. Through GSEA based on MDM2 expression, we found that the ERBB2 signaling pathway was significantly activated in the MDM2-H group, which indicated that MDM2 amplification may induce primary resistance to EGFR-TKIs via the ERBB2 signaling pathway. In addition to effects on the ERBB2 signaling pathway, PDGF was significantly up-regulated in the MDM2-H group. In our previous review (Hou et al. 2019b), MDM2 overexpression up-regulated the expression of PDGF and vascular endothelial growth factor (VEGF), which contributed to sustained cancerous angiogenesis and induced resistance to EGFR-TKIs. Therefore, MDM2 amplification activates multiple pathways and enables tumor cells to develop resistance to EGFR-TKIs. Admittedly, some limitations exist in our 
Golding B, Luu A, Jones R, et al. The function and therapeutic targeting of anaplastic lymphoma kinase (ALK) in non-small cell lung cancer (NSCLC). Mo Cancer. 2018;17:52.

Hou HL, Ge C, Sun HF, et al. Tunicamycin inhibits cell proliferation and migration in hepatocellular carcinoma through suppression of CD44s and the ERK1/2 pathway. Cancer Sci. 2018b;9(4):1088-100.

Hou HL, Sun DT, Liu KW, et al. The safety and serious adverse events of approved ALK inhibitors in malignancies: a meta-analysis. Cancer Manag Res. 2019a;11: 4109-18.

Hou HL, Sun DT, Zhang XC. The role of MDM2 amplification and overexpression in therapeutic resistance of malignant tumors. Cancer Cell Int. 2019b;19:216-69.

Hou HL, Zhu H, Zhao H, et al. Comprehensive molecular characterization of young chinese patients with lung adenocarcinoma identified a distinctive genetic profile. Oncologist. 2018a;23(9):1008-15.

Inukai $\mathrm{M}$, Toyooka S, Ito $\mathrm{S}$, et al. Presence of epidermal growth factor receptor gene T790M mutation as a minor clone in non-small cell lung cancer. Cancer Res. 2006;66:854-8.

Kato S, Goodman A, Walavalkar V, et al. Hyperprogressors after immunotherapy: analysis of genomic alterations associated with accelerated growth rate. Clin Cancer Res. 2017;23:4242-50.

Kim Y, Lee B, Shim JH, et al. Concurrent genetic alterations predict the progression to target therapy in EGFR-mutated advanced NSCLC. J Thorac Oncol. 2019:14:193-202.

Koom WS, Park SY, Kim W, et al. Combination of radiotherapy and adenovirusmediated p53 gene therapy for MDM2-overexpressing hepatocellular carcinoma. J Radiat Res. 2012;53:202-10.

Lee Y, Lee GK, Lee YS, et al. Clinical outcome according to the level of preexisting epidermal growth factor receptor T790M mutation in patients with lung cancer harboring sensitive epidermal growth factor receptor mutations. Cancer. 2014;120:2090-8.

Li T, Ling YH, Goldman ID, et al. Schedule-dependent cytotoxic synergism of pemetrexed and erlotinib in human non-small cell lung cancer cells. Clin Cancer Res. 2007;13:3413-22.

Mok TS, Wu YL, Thongprasert S, et al. Gefitinib or carboplatin-paclitaxel in pulmonary adenocarcinoma. N Engl J Med. 2009;361:947-57.

Paez JG, Janne PA, Lee JC, et al. EGFR mutations in lung cancer: correlation with clinical response to gefitinib therapy. Science. 2004;304:1497-500.

Recondo G, Facchinetti F, Olaussen KA, et al. Making the first move in EGFRdriven or ALK-driven NSCLC: first-generation or next-generation TKI? Nat Rev Clin Oncol. 2018:15(11):694-708.

Santoni-Rugiu E, Melchior LC, Urbanska EM, et al. Intrinsic resistance to EGFRtyrosine kinase inhibitors in EGFR-mutant non-small cell lung cancer: differences and similarities with acquired resistance. Cancers (Basel). 2019; 11(7):923.

Sharma SV, Lee DY, Li B, et al. A chromatin-mediated reversible drug-tolerant state in cancer cell subpopulations. Cell. 2010;141:69-80.

Takezawa K, Pirazzoli V, Arcila ME, et al. HER2 amplification: a potential mechanism of acquired resistance to EGFR inhibition in EGFR-mutant lung cancers that lack the second-site EGFRT790M mutation. Cancer Discov. 2012; 2:922-33.

Tan CS, Gilligan D, Pacey S. Treatment approaches for EGFR-inhibitor-resistant patients with non-small-cell lung cancer. Lancet Oncol. 2015;16:e447-59.

Tang Z, Li C, Kang B, et al. GEPIA: a web server for cancer and normal gene expression profiling and interactive analyses. Nucleic Acids Res. 2017;45(W1): W98-W102.

Turke AB, Zejnullahu K, Wu YL, et al. Preexistence and clonal selection of MET amplification in EGFR mutant NSCLC. Cancer Cell. 2010;17:77-88.

Wang S, Su X, Bai H, et al. Identification of plasma microRNA profiles for primary resistance to EGFR-TKIs in advanced non-small cell lung cancer (NSCLC) patients with EGFR activating mutation. J Hematol Oncol. 2015;8:127.

Xu J, Shen L, Zhang BC, et al. HER2 overexpression reverses the relative resistance of EGFR-mutant H1975 cell line to gefitinib. Oncol Lett. 2016;12:5363-9.

Yano S, Wang W, Li Q, et al. Hepatocyte growth factor induces gefitinib resistance of lung adenocarcinoma with epidermal growth factor receptoractivating mutations. Cancer Res. 2008;68:9479-87.

Yoshida T, Ishii G, Goto K, et al. Podoplanin-positive cancer-associated fibroblasts in the tumor microenvironment induce primary resistance to EGFR-TKIs in lung adenocarcinoma with EGFR mutation. Clin Cancer Res. 2015;21:642-51.

Yu HA, Suzawa K, Jordan E, et al. Concurrent alterations in EGFR-mutant lung cancers associated with resistance to EGFR kinase inhibitors and characterization of MTOR as a mediator of resistance. Clin Cancer Res. 2018; 24:3108-18.

Zhang M, Liu S, Chua MS, et al. SOCS5 inhibition induces autophagy to impair metastasis in hepatocellular carcinoma cells via the PI3K/Akt/mTOR pathway. Cell Death Dis. 2019;10:612

\section{Publisher's Note}

Springer Nature remains neutral with regard to jurisdictional claims in published maps and institutional affiliations.
Ready to submit your research? Choose BMC and benefit from:

- fast, convenient online submission

- thorough peer review by experienced researchers in your field

- rapid publication on acceptance

- support for research data, including large and complex data types

- gold Open Access which fosters wider collaboration and increased citations

- maximum visibility for your research: over $100 \mathrm{M}$ website views per year

At BMC, research is always in progress.

Learn more biomedcentral.com/submissions 